\title{
Maturation process of regenerated tissues after single-stage simultaneous autologous particulated cartilage implantation and open wedge high tibial osteotomy for articular cartilage defects with medial osteoarthritis of bilateral knees: a case report
}

Yasushi Oshima* (D), Norishige lizawa, Shinro Takai and Tokifumi Majima

\begin{abstract}
Background: Open wedge high tibial osteotomy (OWHTO) is an effective treatment option for young and middleaged active patients with medial unicompartmental knee osteoarthritis $(\mathrm{OA})$. In addition, particulated cartilage implantation has been developed as a simple procedure for cartilage regeneration. Thus, to improve the OWHTO outcomes, a single-stage, simultaneous bilateral knee arthroscopic particulated cartilage implantation with OWHTO was performed.

Case presentation: A 60-year-old male patient presented with severe bilateral knee pain, with grade 2 varus knee OA of the Kellgren-Lawrence classification. Primary arthroscopic evaluations based on the International Cartilage Repair Society grading system showed grade $3 \mathrm{c}$ articular cartilage defects of $1.5 \mathrm{~cm}$ in diameter at the center of the bilateral medial femoral condyles. Following bilateral OWHTO, the healthy cartilage tissue was harvested from the lateral wall of the unilateral femoral intercondylar notch and minced with the cartilage processor. Then, subchondral drillings and cartilage fragment implantations into the bilateral defects were performed arthroscopically. One year postsurgery, second-look arthroscopy findings revealed that the defects were filled with cartilage-like tissues. The maturation process of the regenerated tissues was confirmed with T2 mapping magnetic resonance imaging during the 3-year follow-up period. The patient could walk without a cane, and all Knee Injury and Osteoarthritis Outcome Score parameters were improved without any correction loss in 3 years.
\end{abstract}

* Correspondence: $y$-oshima@nms.ac.jp

Department of Orthopaedic Surgery, Nippon Medical School, 1-1-5 Sendagi,

Bunkyo-ku, Tokyo 113-8603, Japan

C C The Author(s). 2021 Open Access This article is licensed under a Creative Commons Attribution 4.0 International License, which permits use, sharing, adaptation, distribution and reproduction in any medium or format, as long as you give appropriate credit to the original author(s) and the source, provide a link to the Creative Commons licence, and indicate if changes were made. The images or other third party material in this article are included in the article's Creative Commons licence, unless indicated otherwise in a credit line to the material. If material is not included in the article's Creative Commons licence and your intended use is not permitted by statutory regulation or exceeds the permitted use, you will need to obtain permission directly from the copyright holder. To view a copy of this licence, visit http://creativecommons.org/licenses/by/4.0/. The Creative Commons Public Domain Dedication waiver (http://creativecommons.org/publicdomain/zero/1.0/) applies to the data made available in this article, unless otherwise stated in a credit line to the data. 
Conclusions: This is the first report to evaluate the maturation process of the implanted particulated cartilage tissue with T2 mapping magnetic resonance imaging for 3 years. The effect of chondral resurfacing procedure with OWHTO remains unclear; however, the implantation of arthroscopic particulated cartilage fragments is a singlestage and less-invasive procedure. This treatment could regenerate cartilage-like tissue in the present case. Therefore, this additional procedure could potentially improve the long-term outcomes of OWHTO.

Keywords: Case report, Knee osteoarthritis (knee OA), Open wedge high tibial osteotomy (OWHTO), Particulated cartilage implantation, T2 mapping magnetic resonance imaging

\section{Background}

Medial open wedge high tibial osteotomy (OWHTO) is regarded as an effective joint-preserving procedure for young and middle-aged active patients with medial unicompartmental knee osteoarthritis (OA) [1]. Chondral resurfacing procedures, such as subchondral drilling, microfracture, and abrasion arthroplasty, in combination with OWHTO have also been reported to promote cartilage regeneration [2]. More recently, an alternative method in the form of a single-stage particulated cartilage tissue implantation has gained attention for its simplicity, low cost, and potential to repair articular cartilage defects [3].

We present a 3-year follow-up case report of a simultaneous bilateral subchondral drilling, particulated cartilage implantation, and OWHTO for a middle-aged OA patient. The process of cartilage regeneration was observed under T2 mapping magnetic resonance imaging (MRI) during patient follow-up.

\section{Case presentation}

A patient was a 60 -year-old male who complained of severe bilateral knee pain. The patient was administrated nonsteroidal anti-inflammatory drugs, corticosteroids, and hyaluronic acid intraarticular injection for 2 years at the former clinic. However, the symptoms worsened, and he was referred to our hospital for the consideration of surgical treatment. The bilateral knee range of motion (ROM) was limited to be $-10^{\circ}$ in extension and $130^{\circ}$ in flexion, and he walked with the help of two canes.

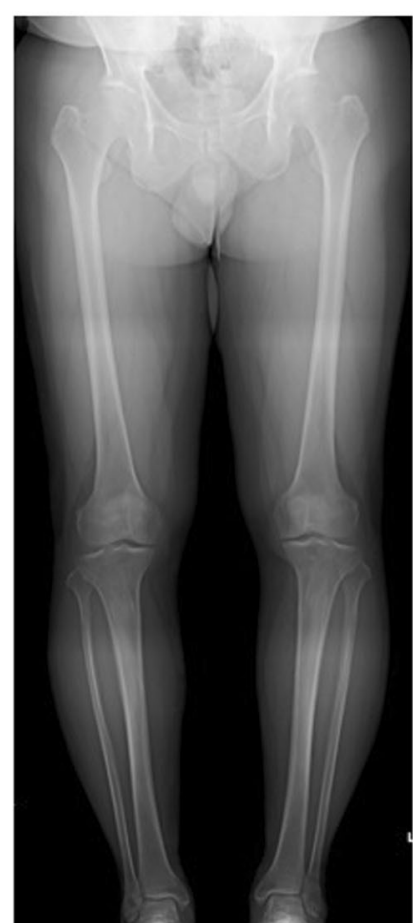

(a)

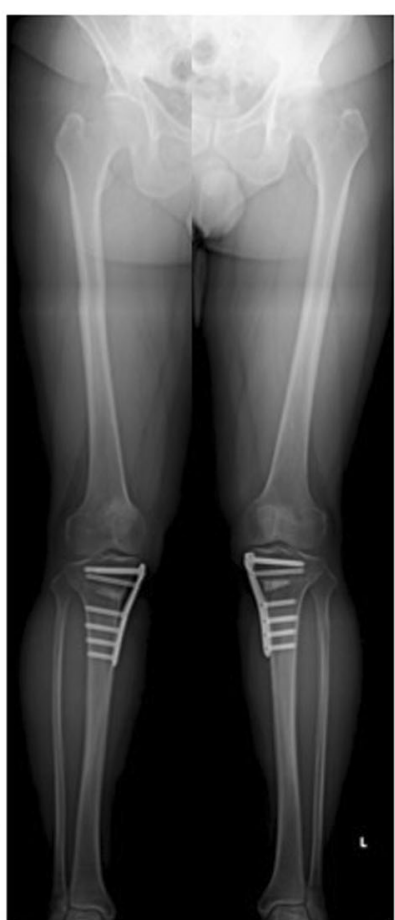

(b)

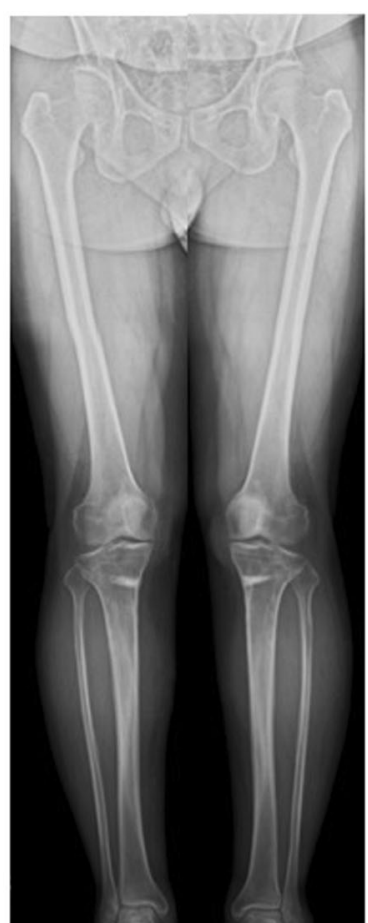

(c)

Fig. 1 (a) Radiographical examination using a standing full weight-bearing lower extremity teleroentgenogram revealed varus knee angulation with a hip-knee-ankle (HKA) angle of $-2^{\circ}$ on the right and $-4^{\circ}$ on the left. (b) HKA angles were $+4^{\circ}$ valgus on the right and $+5^{\circ}$ valgus on the left 1 year after bilateral OWHTO. (c) Alignments of the lower extremities were preserved without correction loss 3 years after bilateral OWHTO and 2 years after the removal of fixations 
Radiographical examinations showed bilateral grade 2 knee OA in the Kellgren-Lawrence classification with a hip-knee-ankle (HKA) angle of $-2^{\circ}$ on the right and $4^{\circ}$ on the left (Fig. 1a). Because of the severe pain and decrease in the activity of daily living, around the knee osteotomy surgery was performed at our hospital.

Arthroscopic evaluations revealed that the articular cartilage at the medial femoral condyle was softened and could be easily detached from the subchondral bone; the defects were classified as grade $3 \mathrm{c}$ according to the International Cartilage Repair Society (ICRS) grading system [4]. The degenerated cartilage was removed using a curette, and the defects measured $1.5 \mathrm{~cm}$ in diameter in both knees.
Bilateral OWHTO was performed with a correction angle of $8^{\circ}$ on the right and $9^{\circ}$ on the left, and the tibiae were fixed using beta-tricalcium phosphate spacers (Osferion 60, Olympus Terumo Biomaterials, Tokyo, Japan) and titanium locking plates (TriS medial HTO plate system, Olympus Terumo Biomaterials, Tokyo, Japan) (Fig. 1b) [5].

Approximately $0.5 \times 2 \mathrm{~cm}^{2}$-sized cartilage tissues were harvested from the lateral wall of the unilateral femoral intercondylar notch and minced with the cartilage processor (Reveille Cartilage Processor, Exactech Inc., Gainesville, FL, USA). The subchondral drilling technique was applied using a $1.8 \mathrm{~mm}$ Kirschner wire at a depth of $8 \mathrm{~mm}$ and a distance of $4 \mathrm{~mm}$. After perfusate

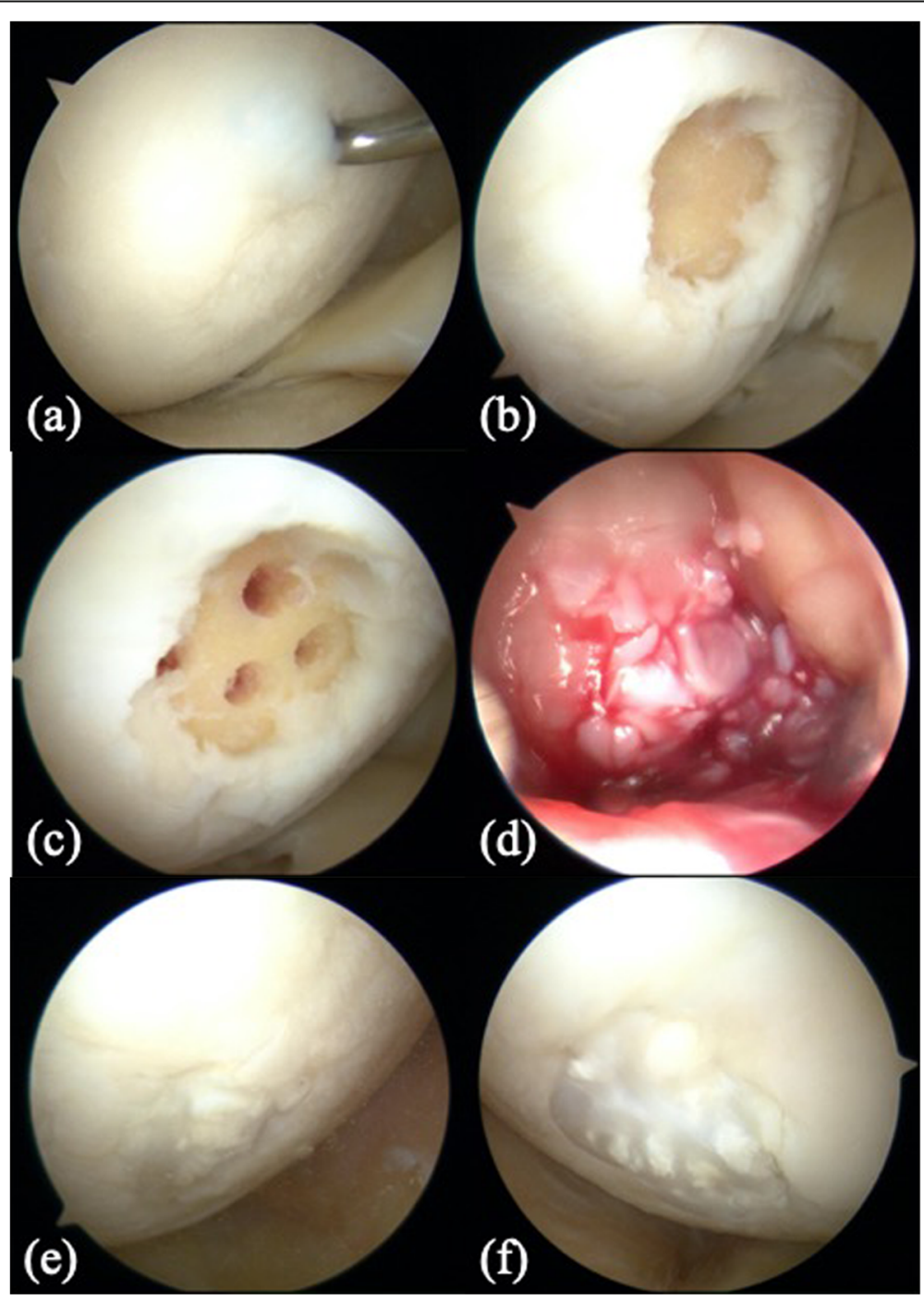

Fig. 2 Arthroscopic findings and surgical procedures. (a) Softening of the articular cartilage at the medial femoral condyle was detected in the right knee. (b) Cartilage was debrided using a curette, and the defect was $1.5 \mathrm{~cm}$ in diameter. (c) Subchondral bone was drilled using a $1.8 \mathrm{~mm}$ Kirschner wire. (d) After dehydrating the knee joint, the particulated cartilage fragments were implanted into the defects and covered with fibrin glue. (e, f) Second-look arthroscopy evaluations demonstrated that the defects were filled with cartilage-like tissues on the right (e) and left (f) 
dehydration in the joint cavity, the particulated cartilage fragments were implanted and covered with fibrin glue arthroscopically (Beriplast, CLS Behring, King of Prussia, PA, USA) (Fig. 2).

The rehabilitation protocol was performed as per a previous report [3]. After surgery, the knee ROM exercise was initiated at up to $30^{\circ}$ for 3 weeks, up to $60^{\circ}$ for 6 weeks, and up to $90^{\circ}$ for 8 weeks, and the full ROM exercise was permitted at 9 weeks. Partial weight-bearing (30\%) was initiated at 3 weeks, $60 \%$ weight-bearing was initiated at 5 weeks, and full weight-bearing was allowed at 7 weeks.

Internal fixation removal with second-look arthroscopy was performed 13 months postoperatively. The defects were confirmed to be filled with regenerated tissues, which were mostly similar height level to the surrounding cartilage. The tissues integrated into the adjacent articular cartilage, and the demarcating borders were $<1 \mathrm{~mm}$. Using a probe, the hardness of the surface at the regenerated tissues was found to be similar to the cartilage. Whitish spots were observed in the regenerated tissues, which were considered as the remaining original particulated cartilage matrix. Macroscopic appearance was not of an intact smooth surface; however, fibrillated change was undetected. From these findings, the regenerated tissues were diagnosed as grade II (nearly normal) with 9 out of 12 points in the ICRS cartilage repair assessment [4]. The donor site was also filled with fibrous tissue; however, the degenerated change was not observed at the surrounding articular surface. The bilateral knee ROM was increased to $0^{\circ}$ in extension and $135^{\circ}$ in flexion. All parameters of the
Knee Injury and Osteoarthritis Outcome Score (KOOS) were improved without any correction loss in 3 years (Fig. 1c and 3). The maturation process of regenerated cartilage-like tissues was also observed under T2 mapping MRI (Fig. 4).

The patient felt a slight knee pain (75 in KOOS) during walking; however, it was improved from 33 in KOOS before the surgery, and he could walk without a cane for an hour. Thus, he felt satisfied with the surgical procedure using particulated cartilage implantation and OWHTO.

\section{Discussion and conclusion}

The maturation processe of the regenerated tissues after single-stage bilateral autologous particulated cartilage implantation, subchondral drilling, and OWHTO was observed in T2 mapping MRI along with the improvement of clinical outcomes in a 3-year follow-up period.

The clinical results of OWHTO have been shown to be promising [6]. Moreover, the 10-year survival rate has been reported at $80-90 \%$ [1]. Furthermore, degenerated cartilage was previously confirmed to be covered with the repaired cartilage tissues only after OWHTO and without any additional chondral resurfacing techniques [7]. Thus, OA progression has been shown to decelerate in addition to knee pain relief after OWHTO, and the long-term clinical and radiological deterioration has been confirmed after OWHTO [8].

For the ICRS grade 3 defects, the regenerated tissues after OWHTO without any additional treatment have been confirmed as immature fibrocartilage tissues [9]. Therefore, in addition to the debridement of partially

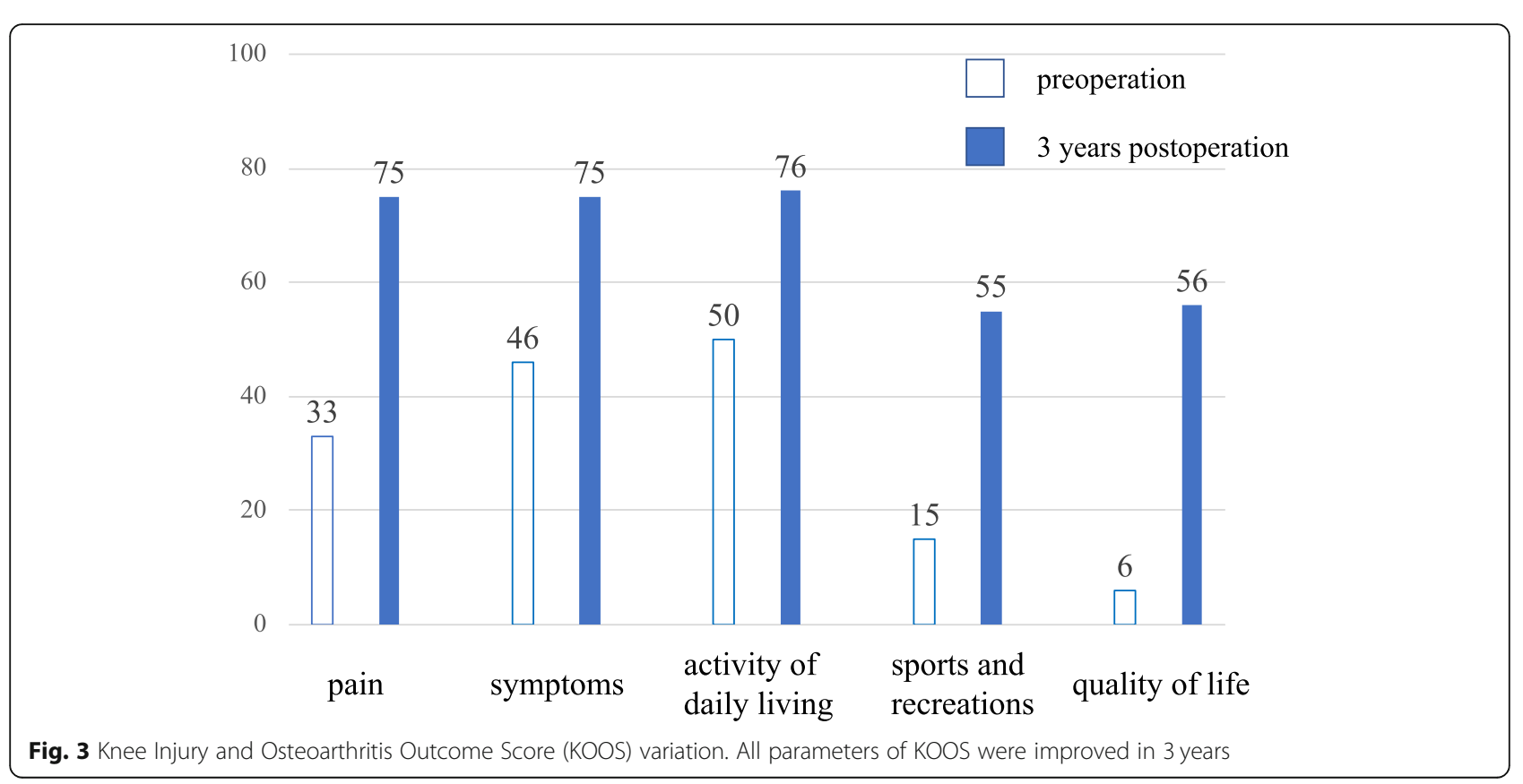




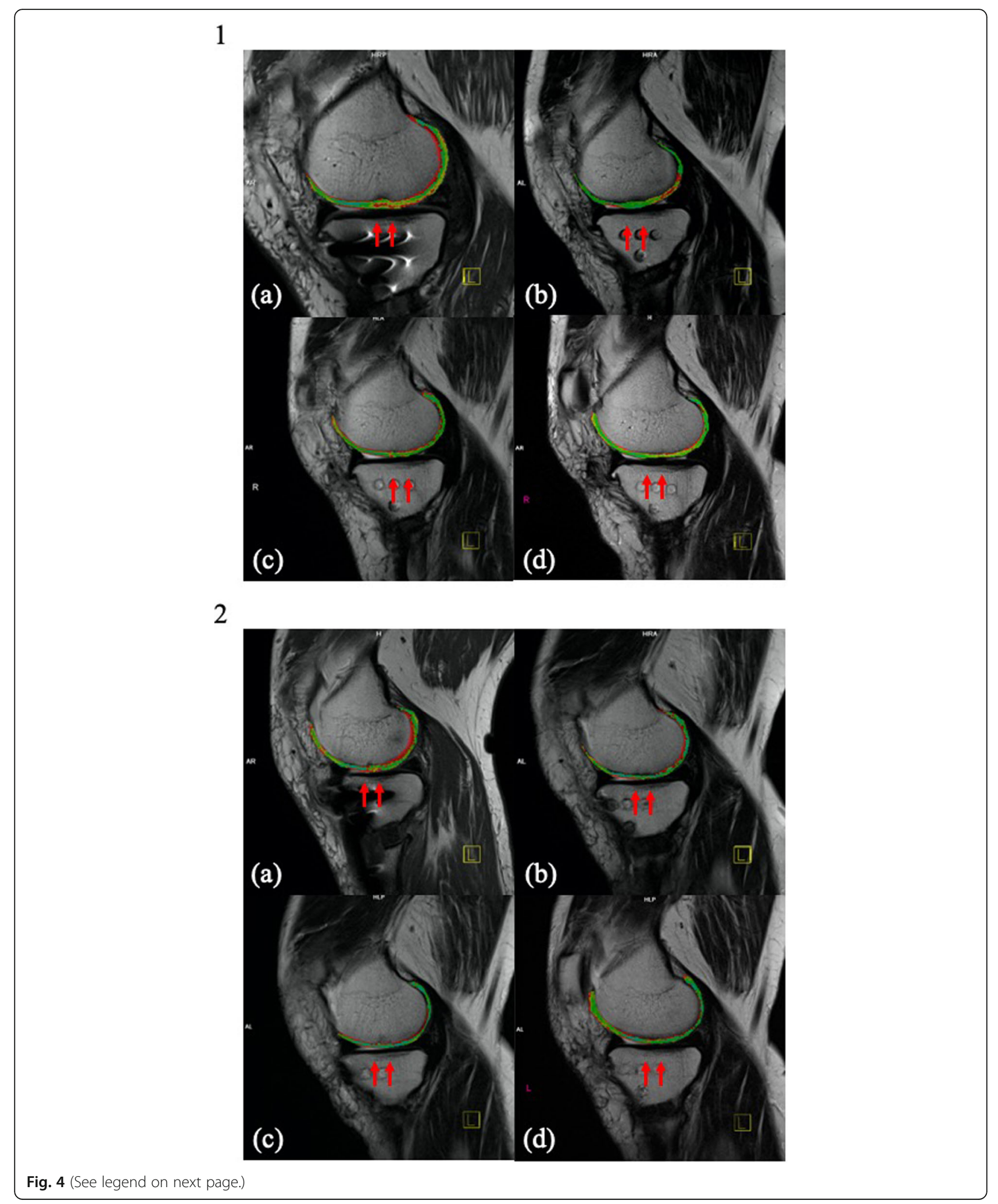


(See figure on previous page.)

Fig. 4 T2 mapping magnetic resonance examinations. (4-1) right knee, (4-2) left knee; the arrows illustrate the implanted sites. (4-1-a) On the right knee, the thicker regenerated tissues with abnormal signals were detected at the implanted site 6 months after the primary surgery. (b) The thickness of the regenerated tissues was still slightly greater than that of the surrounding cartilage; however, the abnormal signals were decreased 14 months after the primary surgery and 1 month after the removal of the fixations. (c) The thickness and signal of the regenerated tissues became similar to those of the surrounding cartilage 2 years after the primary surgery. (d) The regenerated tissues were preserved 3 years after the primary surgery. (4-2-a) On the left knee, the surface was not smooth, and abnormal signals were detected at the implanted site 3 months after the primary surgery. (b) The surface was still slightly irregular, and abnormal signals were detected 14 months after the primary surgery and 1 month after the removal of the fixations. (c) The thickness of the regenerated tissues became similar, and the signals were almost the same as those of the surrounding cartilage 2 years after the primary surgery. (d) The maturation of the regenerated tissues was observed 3 years after the primary surgery

detached cartilage fragments, further treatments, such as the subchondral bone stimulation (drilling and microfracture) and perichondral or periosteal grafting, have been considered. The osteochondral graft and the cultured chondrocyte implantation have also been regarded as treatment options [4]. Nevertheless, a successful cartilage repair of chondral resurfacing procedures in OWHTO has been shown not to improve the clinical and radiological outcome [2]. Thus, the need and effect of these procedures remain unclear; however, several techniques have been suggested in combination with OWHTO to obtain cartilage regeneration and improved long-term outcomes.

In the present case, subchondral drilling and particulated cartilage tissue implantation in combination with OWHTO were performed for ICRS grade $3 \mathrm{c}$ defects with varus knee deformity. The use of minced cartilage for hyaline cartilage repair has been practiced in Germany since 1983. Its promising clinical outcomes have been recently reported with the migration of chondrocytes from cartilage chips and new extracellular matrix formation as well as the survivability of the chondrocytes after cartilage was minced with sharp instruments [10-12]. The particle size of minced cartilage was approximately $0.3-1.0 \mathrm{~mm}$ in diameter, and the operation was performed on $<4 \mathrm{~cm}^{2}$-sized cartilage defects. As the present cartilage processor system involves autologous tissue transplantation with single-stage surgery, it eliminates graft rejection. Moreover, it is cost-effective and only requires $10-15 \mathrm{~min}$ for the harvest, preparation, transplantation, and fixation of the cartilage tissues.

Using this procedure, we observed the maturation processe of the regenerated tissues near the surrounding native hyaline cartilage using T2 mapping MRI. T2 mapping is a quantitative technique that evaluates the interaction of water molecules and collagen network within the articular cartilage. This technique distinguishes the hyaline cartilage from the fibrocartilage [13, 14]. As defects were shown to be repaired with the matured hyaline-like cartilage, the long-term outcome can be improved using this transplantation method rather than repairing the defect with fibrocartilage tissue.
This present case involves some limitations that the histological and biomechanical evaluations of the regenerated tissues were not performed. However, the singlestage surgery and arthroscopic procedure were inexpensive and less invasive. Moreover, the maturation processe of the regenerated cartilage-like tissues with the improvement of clinical outcomes was noted. The benefit of chondral resurfacing procedure combined with OWHTO is, however, still unclear. Therefore, further evaluations are necessary. Nonetheless, particulated cartilage implantation with OWHTO could potentially repair medial $\mathrm{OA}$ in active patients for a long-term benefit.

\section{Abbreviations \\ OWHTO: Open wedge high tibial osteotomy; OA: Osteoarthritis; MRI: Magnetic resonance imaging; ROM: Range of motion; HKA angle: Hip- knee-ankle angle; ICRS: International Cartilage Repair Society; KOOS: Knee Injury and Osteoarthritis Outcome Score}

\section{Acknowledgements}

Not applicable.

\section{Authors' contributions}

YO performed the surgical procedure, analyzed the data, and drafted the manuscript. NI performed the surgical procedure and analyzed the data. ST performed the surgical procedure and helped draft the manuscript. TM supervised this study and helped draft the manuscript. All authors have read and approved the final manuscript.

\section{Funding}

There is no funding to be declared.

\section{Availability of data and materials}

All data generated or analyzed during this study are included in this published article.

\section{Declarations}

Ethics approval and consent to participate

The patient provided written informed consent for participation in the study.

\section{Consent for publication}

Written consent to publish this case information with the personal and clinical details and images was obtained from the patient using our institutional consent form.

\section{Competing interests}

The authors declare that they have no competing interests. 
Received: 6 January 2021 Accepted: 17 May 2021

Published online: 31 May 2021

\section{References}

1. Jin C, Song EK, Santoso A, Ingale PS, Choi IS, Seon JK. Survival and risk factor analysis of medial open wedge high Tibial osteotomy for Unicompartment knee osteoarthritis. Arthroscopy. 2020;36(2):535-43. https://doi.org/10.1016/ j.arthro.2019.08.040.

2. Lee OS, Lee SH, Mok SJ, Lee YS. Comparison of the regeneration of cartilage and the clinical outcomes after the open wedge high tibial osteotomy with or without microfracture: a retrospective case control study. BMC Musculoskelet Disord. 2019;20(1):267. https://doi.org/10.1186/s12891-019-2 607-z.

3. Farr J, Cole BJ, Sherman S, Karas V. Particulated articular cartilage: CAIS and DeNovo NT. J Knee Surg. 2012;25(1):23-9. https://doi.org/10.1055/s-0031-12 99652.

4. Brittberg $\mathrm{M}$, Winalski CS. Evaluation of cartilage injuries and repair. J Bone Joint Surg Am. 2003;85-A(Suppl 2):58-69.

5. Takeuchi R, Aratake M, Bito H, Saito I, Kumagai K, Hayashi R, et al. Clinical results and radiographical evaluation of opening wedge high tibial osteotomy for spontaneous osteonecrosis of the knee. Knee Surg Sports Traumatol Arthrosc. 2009;17(4):361-8. https://doi.org/10.1007/s00167-0080698-4.

6. Goldhahn S, Takeuchi R, Nakamura N, Nakamura R, Sawaguchi T. Responsiveness of the knee injury and osteoarthritis outcome score (KOOS) and the Oxford knee score (OKS) in Japanese patients with high tibial osteotomy. J Orthop Sci. 2017;22(5):862-7. https://doi.org/10.1016/j.jos.2017. 04.013.

7. Kim Kl, Seo MC, Song SJ, Bae DK, Kim DH, Lee SH. Change of chondral lesions and predictive factors after medial open-wedge high Tibial osteotomy with a locked plate system. Am J Sports Med. 2017;45(7):161521. https://doi.org/10.1177/0363546517694864.

8. McClelland D, Barlow D, Moores TS, Wynn-Jones C, Griffiths D, Ogrodnik PJ, et al. Medium- and long-term results of high tibial osteotomy using Garches external fixator and gait analysis for dynamic correction in varus osteoarthritis of the knee. Bone Joint J. 2016;98-B(5):601-7. https://doi.org/1 0.1302/0301-620X.98B5.34875

9. Jung WH, Takeuchi R, Chun CW, Lee JS, Ha JH, Kim JH, et al. Second-look arthroscopic assessment of cartilage regeneration after medial openingwedge high tibial osteotomy. Arthroscopy. 2014;30(1):72-9. https://doi.org/1 0.1016/j.arthro.2013.10.008

10. Christensen BB, Foldager CB, Jensen J, Lind M. Autologous dual-tissue transplantation for osteochondral repair: early clinical and radiological results. Cartilage. 2015;6(3):166-73. https://doi.org/10.1177/194760351 5580983.

11. Lu Y, Dhanaraj S, Wang Z, Bradley DM, Bowman SM, Cole BJ, et al. Minced cartilage without cell culture serves as an effective intraoperative cell source for cartilage repair. J Orthop Res. 2006;24(6):1261-70. https://doi.org/10.1 002/jor.20135.

12. Redman SN, Dowthwaite GP, Thomson BM, Archer CW. The cellular responses of articular cartilage to sharp and blunt trauma. Osteoarthr Cartil. 2004;12(2):106-16. https://doi.org/10.1016/j.joca.2002.12.001.

13. Chen Q, Zuo Q, Hu Q, Feng Y, Cui W, Fan W, et al. Morphological MRI and T2 mapping of cartilage repair tissue after mosaicplasty with tissueengineered cartilage in a pig model. J Biomed Res. 2014;28(4):309-19. https://doi.org/10.7555/JBR.28.20120119.

14. Welsch GH, Mamisch TC, Domayer SE, Dorotka R, Kutscha-Lissberg F, Marlovits S, et al. Cartilage T2 assessment at 3-T MR imaging: in vivo differentiation of normal hyaline cartilage from reparative tissue after two cartilage repair procedures-initial experience. Radiology. 2008;247(1):154-61. https://doi.org/10.1148/radiol.2471070688.

\section{Publisher's Note}

Springer Nature remains neutral with regard to jurisdictional claims in published maps and institutional affiliations.

\section{Ready to submit your research? Choose BMC and benefit from:}

- fast, convenient online submission

- thorough peer review by experienced researchers in your field

- rapid publication on acceptance

- support for research data, including large and complex data types

- gold Open Access which fosters wider collaboration and increased citations

- maximum visibility for your research: over $100 \mathrm{M}$ website views per year

At BMC, research is always in progress.

Learn more biomedcentral.com/submissions 